MATEC Web of Conferences 9, 02010 (2013)

DOI: $10.1051 /$ matecconf/20130902010

(C) Owned by the authors, published by EDP Sciences, 2013

\title{
Mechanism of fire spread on facades and the new Technical Report of EOTA "Large-scale fire performance testing of external wall cladding systems"
}

\author{
Ingolf Kotthoffa and Jan Riemesch-Speer ${ }^{b}$ \\ Ingenieurbüro für Brandschutz bei Fassaden (IBF) / Deutsches Institut für Bautechnik (DIBt) \\ Torstrasse 17, 36457 Stadtlengsfeld / Kolonnenstrasse 30B, 10829 Berlin, Germany
}

\section{INTRODUCTION}

In many European countries it is a requirement to carry out large-scale tests using full-scale test rigs to evaluate the fire performance of external wall cladding systems. The reason for this is that the laboratory test methods (e.g. those according to EN 13501-1 or national standards) used for the classification of the reaction to fire performance of building materials are unsuitable for a realistic simulation of the fire performance of external wall cladding systems. The following reasons can be named:

- Sample measurements are too low

- Fire conditions are too low compared to the effect of fire on a facade due to flames venting from the window of a room with a fully developed fire

- Limited reproduction of facade structures that may promote the spread of fire, such as the suction effect in the air space of ventilated external wall cladding

- No ability to consider detailed formations, such as those around jambs in external wall openings or base finishings

- No ability to consider structural fire safety measures.

For these reasons it was discussed, shortly after the introduction of the European classification system for the reaction to fire performance of building materials in 2002, to include an additional test method for external wall cladding systems. The Fire Regulators Group (FRG), which advises the European Commission (EC) on fire safety matters, even created a working group to deal with this. Its mission was to create an appropriate standardisation mandate for CEN. After intensive preparations it presented the draft mandate in autumn 2004 [1], which contained the key points for the test standard to be developed by CEN.

In addition to this work in the FRG, detailed justifications explaining why such a full-scale test method was necessary for the evaluation of the fire performance of external wall cladding systems were submitted to the services of the European Commission by several Member StateMember States of the EU. Despite this, the EC decided in autumn 2005 not to issue this standardisation mandate. The reason was submitted to the Standing Committee on Construction at the EC in the document CONSTRUCT 05/716rev.1 [2]. However, since the European Organisation for Technical Assessment (EOTA) published or was working on a series of guidelines for the granting of European Technical Approvals (ETA) for construction kits for the fabrication of external wall cladding systems at the time, EOTA received through [2] the task of developing a suitable test method for these products. For this purpose a small working group of representatives from different European approval bodies was formed.

\footnotetext{
ae-mail: IKotthoff@aol.com

be-mail: jsp@dibt.de
}

This is an Open Access article distributed under the terms of the Creative Commons Attribution License 2.0, which permits unrestricted use, distribution, and reproduction in any medium, provided the original work is properly cited. 


\section{MATEC Web of Conferences}

\section{FIRE SPREAD MECHANISMS ON FACADES}

Until around 20 to 25 years ago, the spread of fire over and in facades played only a minor role. The reason for this is that the outer walls mostly comprised massive mineral materials such as brick masonry or concrete coated with a non-combustible rendering. The spread and promotion of fire over the outer surface of external walls due to the ignition of facade components can be ruled out under these conditions. The spread of a fire to another storey only occurred if flames from a fully developed fire emerging from a room impinged on the window in the storey above the location of the fire.

The requirements of facades have changed enormously in the past 15 years. This applies both to their function as the outer building envelope and to their design as the "face" of a building. The efforts to protect the environment and the Earth's natural resources (raw materials) have had a particular impact here. The energy demand for the daily use of buildings - the heating in particular - is one of the biggest items in the consumption of raw materials such as coal, oil or natural gas. In order to decrease it, the energy loss through the building envelope must be reduced dramatically. This inevitably leads to increased demands in the thermal insulation of buildings. Naturally, this affects the external building walls and their cladding as an essential part of the building envelope. In addition, more and more new materials are available on the market that enables a more individual external wall cladding design.

Fulfilling these new requirements of external wall cladding often means using flammable construction materials. For example, the demands on the thermal insulation in low-energy or passive houses require insulation thicknesses of up to $400 \mathrm{~mm}$. Only flammable insulation materials such as polystyrene can be used for this.

With the increased use of flammable materials in external wall cladding it became necessary to suitably evaluate their fire safety properties, considering the real demands in the case of a fire. Determining preventative fire safety measures also requires an exact knowledge of the fire process on external walls. Different studies have been carried out in the last three decades on this subject (e. g. see [3]).

Figure 1 shows the three basic cases that can be distinguished in the effect of fire on external walls.

- Fire of a adjacent building

- Fire outside a building immediately next to the external wall cladding

- Fire in a building in a room with an opening to the external wall.

In case "a)" the surface of an external wall is exposed mainly to heat radiation and briefly to flying sparks, too. The intensity depends heavily on the size of the fire as well as the distance between the neighbouring buildings and their relative position. Only in the case of buildings that are very close to one another and extreme fires is the danger in this scenario comparable to scenarios "b)" and "c)".

In "b)" the following come into consideration as the locations and causes of the exposure to fire:

- Waste containers, bulky waste or parked vehicles at the base of the building

- Furniture, packaging or grills on balconies and patios

- Utility areas of buildings, such as access balconies or sheds, made from flammable materials.

The intensity of the fire impact depends almost entirely on the quantity of fire load present. Oxygen from the air is in sufficient supply for combustion in these cases. In studies by MFPA Leipzig (Leipzig Institute for Materials Research and Testing, see [4]) on different sources of fire (small cars, motorcycles, various waste containers, stored bulky waste) the following figures were determined:

- Maximum heat release rate from 0.4 MW to $2.3 \mathrm{MW}$

- Average heat release rate $0.3 \mathrm{MW}$ to $2.0 \mathrm{MW}$

- Duration of fire between 25 and 45 minutes, whereby the time of the exposure to a fully developed fire was between 10 and 25 minutes

- Maximum height of flames from $2.1 \mathrm{~m}$ to $3.8 \mathrm{~m}$.

In view of these flame heights, external wall cladding even made from non-combustible materials cannot prevent the fire from entering the building if external wall openings are exposed to the fire for a long 


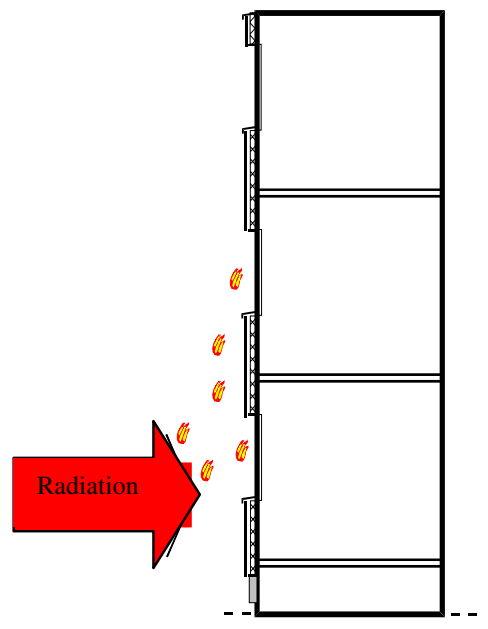

a) Fire of an adjacent building

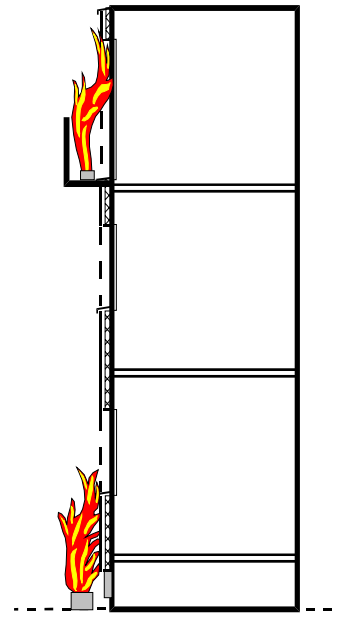

b) Fire outside a building



c) Fire inside a building

Figure 1. Fire scenarios on an external wall of a building (from [4]).

enough period (approx. 10 to 20 minutes). The bottom edge of the windows on the ground floor of a normal building (e.g. a residential building) are usually located approx. $1 \mathrm{~m}$ to $2 \mathrm{~m}$ above the ground level; the bottom edge of the windows in the next storey up are approx. $3.5 \mathrm{~m}$ to $4.5 \mathrm{~m}$ above ground level. If there is flammable external wall cladding present the probability of a fire entering the building increases greatly and the first floor is often affected, too. This applies especially when there are no fire safety measures.

Case "c)" can be viewed as the most critical scenario. If there is sufficient fire load and oxygen in a room adjacent to the external wall, a small initial fire can turn very quickly into a fully developed fire, in which the ignition of as yet unburned pyrolysis products occurs due to heat radiation ("flash-over"). At this point in time at the latest, window panes will break and the flames will vent from the window and impinge upon the facade.

The isotherms in front of the facade shown in Fig. 2 were measured in fire tests for the case of a fully developed fire in a room with flames venting from the window (see [3]).

Since the area of visible flames is approximately the same as the area with a temperature $\geq 500{ }^{\circ} \mathrm{C}$, it is easy to recognise that the flames from the room with the fully developed fire reach - regardless of the type of external wall cladding - at least halfway up the window of the room located above the fire room. This temperature effect lasts for more than 20 minutes and is sufficient for the destruction of the window and the spread of the fire to the next storey. If no fire-fighting measures are introduced the fire will turn into a fully developed fire in this room, too, in the presence of sufficient flammable materials. The flames from this fire will vent from the window and impinge on the window on the next storey up. This is how the fire spreading process restarts via the external building wall from one storey to the next.

In [4] the following figures on the spread of the fire are given for a normal living space with a floor area of $20 \mathrm{~m}^{2}$, a ceiling height of $2.8 \mathrm{~m}$, a $2.0 \times 1.4 \mathrm{~m}$ (width $\times$ height) window opening and a fire load density of approx. $600 \mathrm{MJ} / \mathrm{m}^{2}$ (corresponds approximately to typical furnishing in a home, see also [5]):

- Flash-over between the 7 th and 25 th minute

- Heat release of approx. 5-6 MW in room on fire

- Impact of flames on facade approx 15 - 25 minutes 




Figure 2. Isotherms in front of the facade.

- Heat release of flames in front of facade above lintel approx. $1-2 \mathrm{MW}$

- Height of visible flames above window lintel approx. 2.8 to $3.5 \mathrm{~m}$, intermittent flames up to $6.5 \mathrm{~m}$

- Temperatures in area of lintel approx. $700-900{ }^{\circ} \mathrm{C}$ for a period of 15 to 20 minutes.

The temporal relations for the spread of a fire from storey to storey via the external building wall are shown in figure 3. Similar descriptions are to be found also in [6] and [7].

The mechanisms of fire spread over the facade shown in the figure are only valid if the external wall cladding contributes little or nothing to the fire. If there are any flammable materials on the facade or its design promotes the spread of fire (e.g. due to the suction effect in the air space in ventilated external wall cladding), these processes occur a lot quicker. Due to the enlargement of the flames in front of and in the external wall cladding, the flames reach not only the storey immediately above the room on fire but also the next storey up. This means that the fire spreads almost simultaneously into two storeys. This is also particularly the case when there are no fire safety measures to inhibit this spread of the fire.

The following can be drawn from the aforementioned demonstrations of the fire exposure variations "b)" and "c)": The fire in a room adjacent to an external wall and the flames venting from the window also covers the scenario of a fire outside the building immediately next to the external wall. This is also true because the formation of the external wall cladding in the area of the external wall opening around the lintel is often a weak point, for example due to the use of elastic, flammable joint seals, openings for the ventilation of an air space or missing anchor areas for the reinforcement fabric for the rendering. As described above, this area is exposed particularly heavily to the fire. A special test using a test fire to simulate the fire exposure according to scenario "b)" is only necessary in some cases to evaluate the fire safety design of the finishing of the external wall cladding in the base area of buildings.

A test scenario is required for the realistic evaluation of the influence of external wall cladding on the spread and promotion of fire over the facade that considers the following key points:

- External wall cladding test rig as close to 1:1 scale as possible and considering the actual formation around the external wall openings

- Simulation of the fire exposure from the time of flash-over in the burning room and the venting of the flames from the external wall opening 


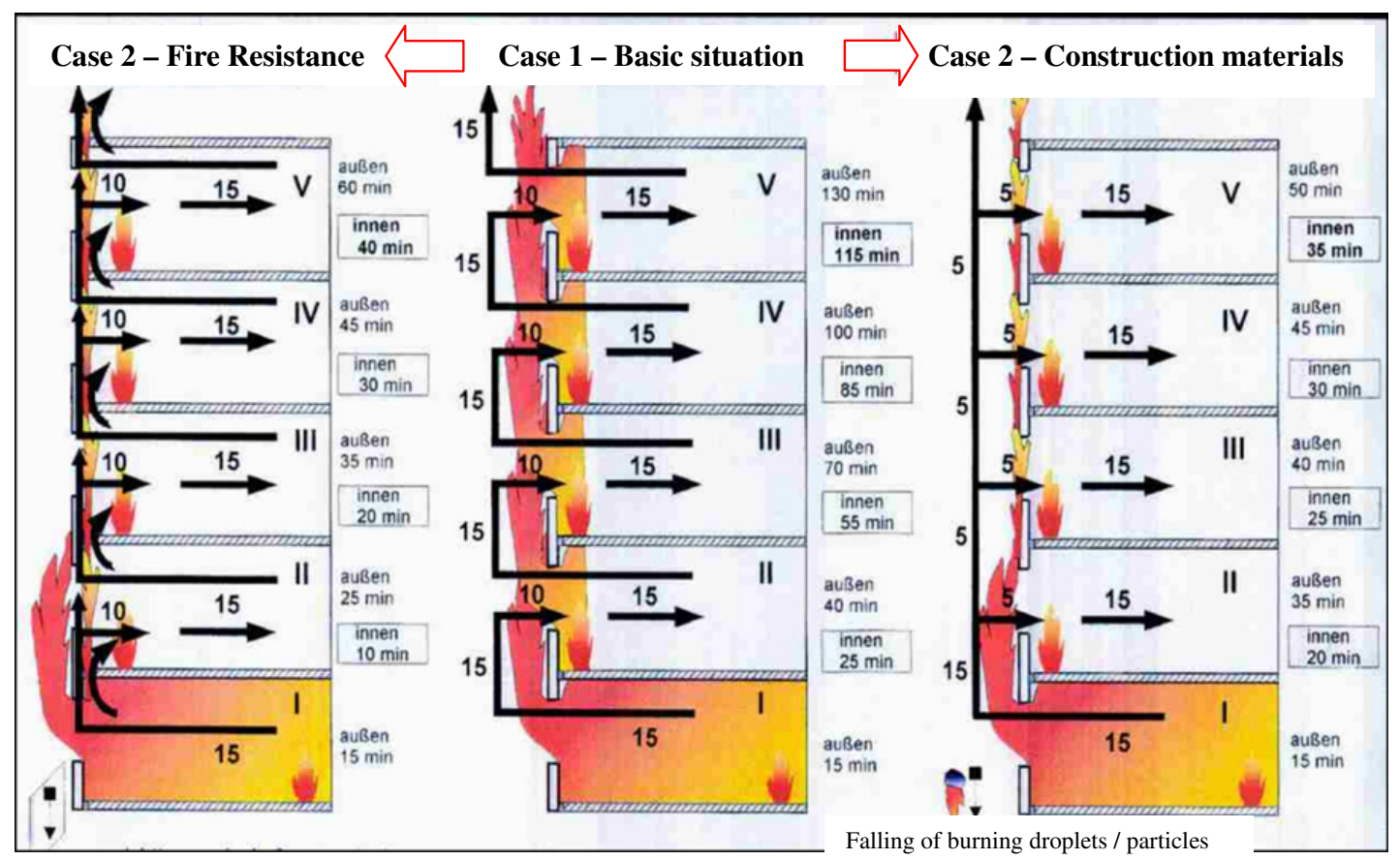

Figure 3. Sequence of spread of fire over the external building wall.

- Continuous exposure to temperatures at the lintel of approx. $800-900^{\circ} \mathrm{C}$ during the test period

- Height of the primary flames from the test fire in front of the facade of at least approx. $2.5 \mathrm{~m}$ during the test period

- Test period of approx. 20 to 30 minutes.

There are test methods in several Member States of the European Union that come very close to these key points (see [8-11], for example). The essential differences between these methods are in the materials used for the test fire and the released energy used.

\section{THE NEW EOTA TECHNICAL REPORT “LARGE SCALE FIRE PERFORMANCE TESTING OF EXTERNAL WALL CLADDING SYSTEMS”}

In autumn 2005 the European Commission decided not to issue a standardisation mandate to CEN for the creation of a fire test method for external wall cladding. Instead, a suitable test method was to be developed at EOTA, in order to be able to evaluate the fire performance of external wall cladding systems that could be granted European Technical Approvals. For this purpose a small task group of representatives from different approval bodies and test bodies was formed by EOTA in May 2006. It had its first meeting in spring 2007. The most important task was to determine which requirements are made regarding external wall cladding systems in the individual Member States and which test methods are used to check that these requirements are met. Responses came from the United Kingdom, France, Sweden, Poland, Hungary, Austria and Germany. This information, together with the draft mandate created by the FRG for the EC [1], formed the basis for the subsequent work of the EOTA task group. 


\section{MATEC Web of Conferences}

The following key points for the development of the test method were specified in annex 4 in [1]:

- Two-stage test with the test rig under a thermal exposure of

- $40 \mathrm{~kW} / \mathrm{m}^{2}$ at a height $x$ above the fire chamber for a minimum of 10 minutes and

- $70 \mathrm{~kW} / \mathrm{m}^{2}$ at a height $y$ above the fire chamber for a further 15 minutes

- Test rig in a corner configuration with a short and a long wing

- Height of the test rig at least $4 \mathrm{~m}$ above fire chamber for stage 1 and at least $6 \mathrm{~m}$ for stage 2

- Arrangement of fire chamber in the long wing of the test rig close to the corner adjacent to the short wing without a distance to the floor of the test rig

- Size of the fire chamber opening $2.0 \mathrm{~m} \times 1.2 \mathrm{~m}$ (width $\times$ height)

- Use of a diffusion flame as the test fire

- External wall cladding under test to be installed professionally, including all fastening and adhesive materials.

In the task group's discussions, it was quickly recognised that the objective of the work was to investigate the contribution of the external wall cladding to the development and spread of fire in the test method being developed. Thus, it concerned an evaluation of the fire performance of the facade system. A fire in a room adjoining the external wall and the flames venting from the window after flash-over was identified as the reference fire scenario. The task group also believed this scenario covers the other cases of the effect of fire on facades (see section 2). Aspects of the fire resistance of external walls, on the other hand, were not to be considered. This meant that curtain walls were excluded from the test. These key points were confirmed after just a few meetings of the working group. The following parameters were viewed as being suitable for the evaluation of the response of the facade to fire:

- Spread of fire on the surface and inside the external wall cladding system (including continuous glowing and smouldering)

- Mechanical response of the external wall cladding system under fire exposure, including flame dripping/falling of droplets.

For these reasons - and after evaluating the information from the Member States on the fire test methods applied to facades - the aforementioned key points from [1] were confirmed in 2007 as the basis for the creation of a test method. In the further work there were only two main deviations from these specifications:

The first point concerned the decision that the sample may be tested, according to the requirements, either with the lower fire exposure for level 1 or with the higher fire exposure for level 2, rather than using the 2 stage test. The consensus of the task group was that it would not be possible, during a running test, to decide to increase the fire exposure from level 1 to level 2.

The second point concerned the use of wooden cribs as the test fire instead of a diffusion gas burner. The crucial point here was that the effort to achieve a correctly working gas burner, especially for exposure level 2, would cause too high financial costs. Furthermore, information on the heat release and the development of smoke is not required in most Member States for the evaluation of the fire performance of external wall cladding systems. The use of a gas burner with an exactly defined heat release would only be necessary for determining these parameters by measuring the depletion of oxygen.

The decision taken by a majority of the EOTA task group on the key points of the test approach and the relevant assessment parameters as described above also means a European acceptance of the fire scenario "Fully developed fire in a room and flames venting out of a window" as reference fire scenario for testing the fire performance of external wall cladding systems. The two possible exposure levels only reflect the different safety levels in the European states.

In 2009, the determination stipulated by the task group had been presented to the Technical Board of EOTA as well as to the Expert Group for Fire-related Issues (EGF) of the European Commission asking for comments. No objections had been made by both committees. As a consequence the members of the task group worked out a detailed test program for verification and validation of the corner stones of the 
test approach until autumn 2010. It should serve as clarification for the following items:

- Design of both wood cribs (wood species, moisture content, density and dimensions of the wood sticks, weight and assembly of the cribs),

- required ventilation conditions,

- energy impact of both wood cribs on the façade and comparison with the recommendations of the draft mandate [1],

- flame lengths of both wood cribs in front of the façade and parameters, which have an effect on these flame lengths,

- necessary instrumentation for the required measurements during testing,

- repeatability and reproducibility of test results executed by various testing laboratories.

Until today, this test program could not be realized due to lack funding. Neither the European Commission nor the approval bodies being member of EOTA or the industry associations involved in the work of the task group were able to provide the necessary funding for executing the test program. Since the European Construction Products Regulation (CPR) has replaced the former European Construction Products Directive (CPD) on 1 July 2013, the task group decided to work out a document until the end of 2012 in which the summary of the current status of the activities should be given. Available experiences from similar national test methods should be applied for those items being subject of the test program. It was the intention to have a document which - if possible - future European Assessment Documents (EAD) can refer to after introduction of the European Construction Products Regulation. This document had been finalized as draft Technical Report "Large-scale fire performance testing of external wall cladding systems" [12] in January 2013 and submitted to the responsible committees of EOTA for discussion and endorsement.

The draft of the Technical Report describes a test approach containing two different exposure levels. As test rig a $90^{\circ}$ corner configuration of the test wall is used, made of aerated concrete and consisting of a long and a short wing. The width of the wing faces are always the same. Only the height of the test rig varies depending on the exposure level used for testing. It amounts to $5.5 \mathrm{~m}$ as minimum for exposure level 1 and to $8.0 \mathrm{~m}$ as minimum for exposure level 2 . The aerated concrete of the test wall represents end-use applications of the external wall cladding systems on non-combustible substrates like masonry or concrete. For the simulation of external walls made of a steel frame structure and faced with wood-based panels on the outer side of the wall the test rig can additionally be equipped with $12 \mathrm{~mm}$ thick particle boards as substrate.

Figure 4 shows isometric views on the test rig for both exposure levels.

The fire load chamber for positioning the wood cribs is placed in the long wing directly on the floor and near the inner corner of the test rig. Deviating from the original commitments of the task group (see above) the fire load chambers have the following dimensions.

- for exposure level 1: $1.0 \times 1.0 \times 0.8 \mathrm{~m}$ (width $\times$ height $\times$ depth) and

- for exposure level 2: $2.0 \times 2.0 \times 1.0 \mathrm{~m}$ (width $\times$ height $\times$ depth).

This deviation is also due to the lacking test of the intended test program and the therefore necessary use of some national experiences. In the middle of the back wall of the fire load chamber for exposure level 1 a circle opening is foreseen for an additional ventilation of $400 \mathrm{~m}^{3}$ /hour air volume flow.

The following wood cribs are prescribed as fire source:

- exposure level 1: about $30 \mathrm{~kg}$ spruce wood, consisting of sticks $40 \times 40 \times 500 \mathrm{~mm}$, mounted in alternating layers of length and cross orientated sticks with a ratio of about 1:1 of wood and air between sticks covering an area of $500 \times 500 \mathrm{~mm}$ an positioned $200 \mathrm{~mm}$ above the floor,

- exposure level 2: about $400 \mathrm{~kg}$ pine wood, consisting of sticks $50 \times 50 \times 1500$ or $1000 \mathrm{~mm}$, stacked to crib with dimensions of $1500 \times 1000 \times 1000 \mathrm{~mm}$ and a ratio of about 1:1 of wood and air between sticks.

The cribs are positioned in the middle of the opening of the fire chamber, but $100 \mathrm{~mm}$ behind the surface of the test rig in case of exposure level 1 and $100 \mathrm{~mm}$ away from the back wall of the fire chamber respectively in case of exposure level 2. 


\section{MATEC Web of Conferences}
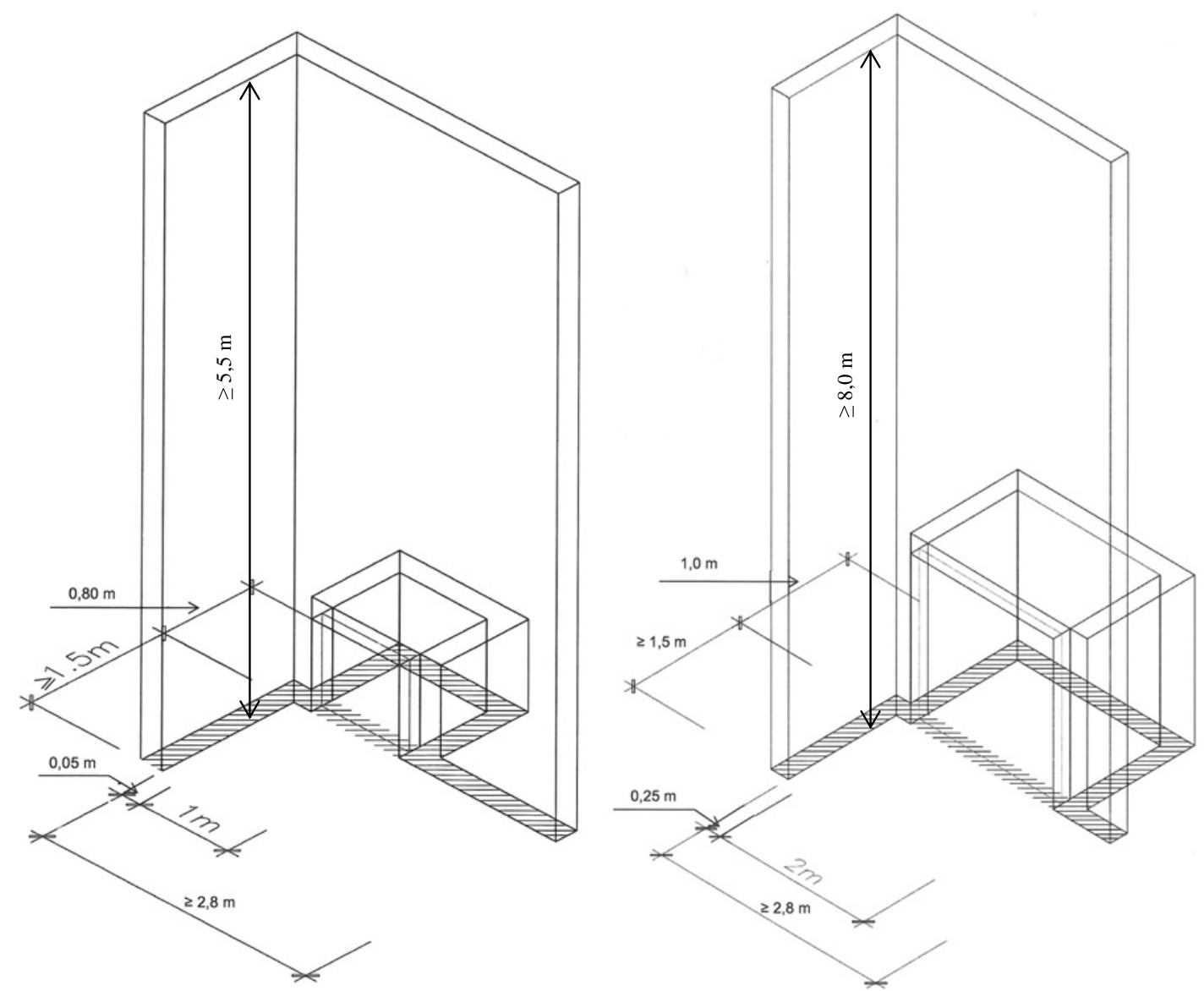

Figure 4. Isometric view of the test rig for exposure level 1 (left side) and exposure level 2 (right side).

After a first calibration test of a 30-kg-wood crib done for orientation by the testing laboratory MFPA Leipzig, Germany, it can be assumed that this fire source is appropriate to simulate a similar fire exposure as determined in tests according to [3] (see figure 2). Figure 5 shows the time-independent maximum isotherms for this wood crib. It is well-visible that the area with temperatures of $\geq 500{ }^{\circ} \mathrm{C}$ reaches a height of about $2.0 \mathrm{~m}$ above the lintel of the fire chamber. The observed flame lengths amount to about $2.0-2.5 \mathrm{~m}$ above the fire chamber.

For the 400-kg-wood crib no calibration data could be presented to the task group.

The test rig for exposure level 1 is similar to the test methods being used in Austria [8] and Germany [9] for many years and it is based on specifications already agreed within the Conseil International du Bâtiment (CIB W14) for fire tests of external wall cladding systems on the scale of 1:1 in the late eighties of the last century. The test rig for exposure level 2 is comparable to the British test approach [10].

For both exposure level 1 and exposure level 2 the testing time to the fire is 30 minutes. After the end of fire exposure a monitoring time follows of at least 30 minutes. This time can be extended to 24 hours as maximum to determine possible glowing or smouldering.

The following parameters

- flame spread (inside and outside the external wall cladding systems),

- temperatures on defined positions of the test assembly,

- occurrence of continuous smouldering or glowing combustion, 


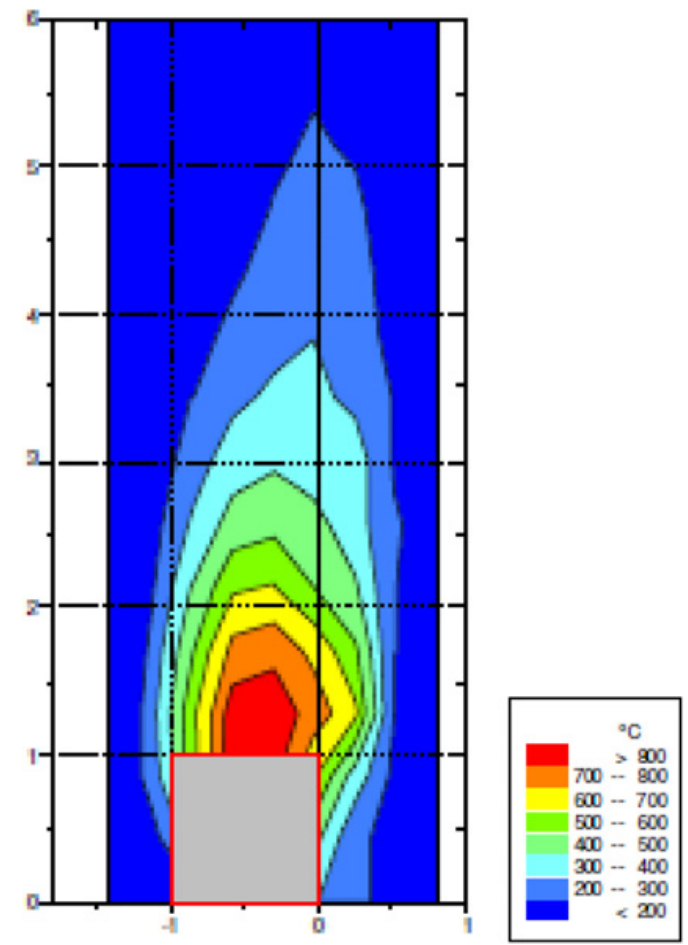

Figure 5. Time-independent maximum isotherms of the 30-kg-wood crib.

- mechanical response, including (but not only) flaming dripping / falling of droplets / parts and collapse of the cladding system as well as

- damaged areas of the test assembly caused by fire

shall be recorded as a basis for the assessment of the fire performance of an external wall cladding system.

Determination of the flame spread as well as the judgement of the mechanical response shall be based on visual observation during testing, supported by a continuous video recording of each test. Thermocouples shall be used for purposes of temperature measurements including detection of continuous glowing or smouldering processes. These thermocouples are mounted in different heights and distances to the test rig as well as inside of the external wall cladding systems to be tested.

Burnt, charred and molten or shrunken areas are distinguished for the assessment of the damage caused by fire after the end of testing. However, discolorations, soot residues, melting shrinking or sintering do not count as areas damaged by burning.

Unlike originally intended and also caused by the missing validation tests the Technical Report does not contain provisions for different performance classes or levels and the conditions for obtaining those classes or levels. For that purpose the execution of the planned test program for verification and validation of the described test approach is mandatory. Currently it is intended to state the test results in European Technical Assessments according to this Technical Report. Then each Member State will have the possibility to decide which conditions regarding the various assessment parameters must be fulfilled for ensuring its national safety level(s) required.

Rules for extended application of test results are also missing in the document. These rules shall be laid down in the relevant product specifications (European Assessment Documents EAD). However, even for that the experiences from the planned test program are needed. 


\section{MATEC Web of Conferences}

The Technical Board of EOTA has been informed on both items. Continuation of work concerning classification criteria as well as rules for extended application of test results depends on the availability of funding. Provided that funding will be available soon the EOTA task group should be able to work out appropriate provisions for both matters in the medium-term.

\section{SUMMARY}

During the past years the essential fundamentals of a test approach had been worked out by a European task group of EOTA for a realistic assessment of the fire performance of external wall cladding systems. The scenario of a fully-developed fire in a room adjacent to an external wall and the exposure of a façade to the effects of flames venting through an opening of this room can be considered as the reference fire scenario accepted in Europe by a majority for the test approach. This fire scenario as worst-case also covers the other possibilities of fire exposure of a façade through burning of an adjacent building or burning outside the building directly in front of the façade.

The test approach complies as far as possible with the key points given in the draft mandate for standardization to CEN, which had been prepared by the former Fire Regulators Group (FRG) until 2004, but was never granted by the European Commission. For taking into consideration the different safety levels in the Member states of EOTA the test approach contains two different exposure levels. The height of the test rig for each exposure levels allows determining the contribution of the external wall cladding system tested to fire propagation and fire spread. On the basis of the results of such tests it can be assessed whether the flames venting trough an external wall opening are extended in such manner by the façade that not only the windows of the storey directly above the fire room will reached but also the windows of the storey after next.

Up to now no tests for verification and validation of the test approach could be executed due to lacking funding. Therefore only limited experiences from similar national test methods are available. For this reason the draft Technical Report does not contain any provisions for different performance classes or levels and the requirements to be fulfilled as well as rules for the extended application of test results. This will be an item of future works of the task group of EOTA, provided that the test program planned can be realized.

\section{References}

[1] Draft mandate "Evaluation of the fire performance and the mechanical response of external wall cladding systems" of the European Commission, version October 2004 - unpublished

[2] Document CONSTRUCT 05/716rev.1 of the European Commission, enterprise and industry directorate-general, dated $24^{\text {th }}$ October 2005- unpublished; only presented to the Standing Committee for Construction

[3] Brandversuche Lehrte (Fire Tests in Lehrte), Schriftenreihe des Bundesministers für Raumordnung, Bauwesen und Städtebau, Issue no. 037, 1978

[4] Ingolf Kotthoff "Grundlagen für die Zulassung und die Normung des Brandverhaltens von Fassadenbekleidungen" (Fundamentals for the Approval and Standardisation of the Fire Performance of Facade Cladding), Tagungsband der Braunschweiger Brandschutztage 2012

[5] EN 1991-1-2:2002 + AC:2009: Eurocode 1: Action on structures - Part 1-2: General actions Action on structures exposed to fire; Annex E.2.5

[6] Sarah Colwell, Brain Martin "Fire performance of external thermal insulation for walls of multistorey buildings" published by BRE / FRS 2003

[7] Ryan Roger, Edward Shipper "ASTM Leap-Frog Effect - The design and analysis of a computer fire model to test for flame spread through a building?s exterior" Worchester Polytechnics Institute, April 2010 
[8] Pre-standard ÖNORM B38005 "Fire performance of construction materials and building elements; part 5: Fire performance of facades - requirements, test methods and assessments" dated $1^{\text {st }}$ May 2004

[9] Working draft DIN 4102-20 "Fire performance of construction materials and building elements; part 20: Special determination of the fire performance of external wall cladding systems" - still unpublished

[10] Standard BS 8414 "Fire performance of external wall cladding systems", part 1 dated $13^{\text {th }}$ December 2002 and part 2 dated $06^{\text {th }}$ October 2005

[11] SP FIRE 105 - Method for fire testing of facade materials, Dnr. 171-79-360 Department of Fire Technology, Swedish National Testing and Research Institute

[12] Draft Technical Report of EOTA "Large-scale fire performance testing of external wall cladding systems", version January 2013, still unpublished 